\title{
Students Enrolled in Biology Majors Pre-Requisite Courses: Effect of High School Academic Performance
}

\author{
Mamta Singh ${ }^{1, *}$, Sandra West ${ }^{2}$ \\ ${ }^{1}$ Martin University, Indianapolis, Indianapolis \\ ${ }^{2}$ Texas State University San Marcos, Texas \\ *Corresponding author: mamtasingh1328@gmail.com
}

Received February 27, 2014; Revised March 15, 2014; Accepted March 19, 2014

\begin{abstract}
The purpose of this study was to enhance the ability of an institution to provide biology major students the best opportunity to succeed. Grades are universally measured variables. Regardless of different instructors teaching the same course in different sections, the final course grade is combined for all the sections representing one course. This study reflects the differences in students as they were successful in courses due to performance verse students who were not successful because of their low performance. The study used logistic regression analysis to assess students' performance in biology major courses. The findings suggest that high school GPA and high school chemistry were the predictors of students' success in entry-level biology courses.
\end{abstract}

Keywords: high school chemistry, GPA, entry-level biology

Cite This Article: Mamta Singh, and Sandra West, "Students Enrolled in Biology Majors Pre-Requisite Courses: Effect of High School Academic Performance.” American Journal of Educational Research, vol. 2, no. 4 (2014): 183-188. doi: 10.12691/education-2-4-1.

\section{Introduction}

It has been widely recognized that academic grades in introductory college science courses are generally considered as reinforcement for college performance. Studying college performance and success in entry-level courses is of prime importance for every department for it enables the departmental personnel to identify the important factors linked with higher student retention and success and to formulate the policy accordingly. Any improvement in the performance of these students will be beneficial to programs, departments, universities or colleges, and the nation as a whole. Research by DesJardins, McCall, Ahlburg, and Moye (2002), Korey (2013); Belfield \& Crosta (2014); Farkas (2014); Strauss (2014) suggested a positive relationship between student high school GPA and college achievement. A study by Cambiano, Denny, and De Vore (2000) suggested that high school preparation had a positive effect on freshmen college performance. Likewise, Nordstorm (1990), Cabrera, Nora, and Castaneda (1993), Hu and St. John (2001), Leppel (2002), Perna (1998), and Tinto (1982) Korey (2013); Belfield \& Crosta (2014); Farkas (2014); Strauss (2014)found that high school GPA was a strong predictor of college student persistence and performance. A study by Johnson (2006) also revealed that students who were more likely to earn a GPA higher than 2.00 were less likely to leave college for academic reasons. Johnson further suggested that high school GPA and SAT score had a positive effect on student persistence and performance and also added that college first-year GPA was the most important factor of student success.
However, the opposite trends were reported by Jones and Watson (1990) and Weissberg, Owen, Jenkins, and Harburg (2003), which suggest that high school performance often failed to predict with a high degree of accuracy, college success because of two associated reasons: first, the high school curriculum may not have prepared the student for college work, and second, the high school GPA were poor predictors of college success due to grade inflation. Also, a lack of standardization in high school grading systems could be considered as a probable cause. Similarly, Sadler and Tai (2000) reported that the number of high school science and math courses completed by students had little influence on students' performance in college science, whereas students' expectations were better predictors of their college science performance. Furthermore, Kulik, Kulik, and Schwalb (1983) and Pascarella and Terenzini (1991) have reported that programs designed to improve students' academic skills have a substantial effect on college success. This poor academic performance in college often forces students to discontinue their academic venture. This performance has been a focus of several studies (American Council on Education, 1996; Sadler \&Tai, 2000; Selingo, 2003; Tai, Sadler, \& Loehr, 2005). "Among the educational reform efforts in the United States, national initiatives often target K-12 education to encourage all students to participate more actively in science education National Research Council (NRC, 1996). Although the rationale behind these efforts is to enhance K-12 students' interest in science, these efforts are not as visible at the college level," (Kahveci, Southerland, and Gilmer, 2006, p 34). The present study attempts to identify predictor variables that were most 
indicative of success for students in entry-level biology pre requisite courses.

\section{Methods}

Data Collection and Analysis: This is a cohort study. There were two sample populations in this study. The participants in sample one included students enrolled in the fall 2007 semester (Cohort One) and the spring 2008 semester (Cohort Two) in two entry-level biology courses (Functional and Organismal Biology) at large research university in southern United States. There were 16 and 18 laboratory sections in Functional and Organismal Biology respectively for both semesters. The average class size was approximately 18 students in each laboratory section. Total no of student participants via cohort and courses are shown in tables 1 and 2. Demographic Information Analysis (DIA) and Logistic Regression Analysis (LRA) were used for data analysis. Before analyzing the data, a series of data screening procedures were completed. First, frequencies were calculated for all predictor variables. Both contingency and correlation matrices were constructed to examine patterns in the data. For the logistic regression analysis, variables were selected based on univariable analysis in which each variable was analyzed separately to determine its prediction of the dependent variable (student success). Any variable whose univariable test statistic had a Wald statistic with a $p$-value
$<0.25$ was a candidate for the multivariable model. This decision was based on the recommendations of several researchers (Bendel \& Afifi, 1977; Hosmer \& Lemeshow, 2000; Mickey \& Greenland, 1989), who suggested that the use of traditional level $p$-value $<0.05$ often fails to identify important variables. Once the selected variables with the $p$ value $<0.25$ were identified, logistic regression models were constructed using all these selected variables (Hosmer \& Lemeshow, 2000). In this process, all candidate independent variables were simultaneously added into the model and only the statistically significant results were reported. Tables present the log odds (beta), the standard error of beta, the Wald statistic, the significance of the Wald statistic, the odds ratio (Exp (B)), and the 95\% confidence interval (CI) of the odds ratio. The odds ratio predicts the probability of the event coded as 1 (student success in courses) and also assesses the magnitude of chance in the probability for a 1-unit change in the independent variable (Hosmer \& Lemeshow, 2000). If the odds ratio is greater than 1 and the regression coefficient is positive, an increase in the independent variable will lead to an increase in the probability of a student being successful. Conversely, if the odds ratio is less than 1 and the regression coefficient is negative, an increase in the independent variable will lead to a decrease in the probability of being successful (Hosmer \& Lemeshow, 2000).

Table 1. Demographic Characteristics of Functional and Organismal Biology Student Participants of Cohort One

\begin{tabular}{|c|c|c|c|c|}
\hline 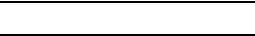 & Functional Biology & & Organismal Biology & \\
\hline Variable & Frequency & Percent & Frequency & Percent \\
\hline \multicolumn{5}{|l|}{ Classification } \\
\hline Freshman & 114 & 34.23 & 105 & 30.97 \\
\hline Sophomore & 92 & 27.62 & 84 & 24.77 \\
\hline Junior & 57 & 17.11 & 79 & 23.30 \\
\hline Senior & 24 & 7.2 & 24 & 7.079 \\
\hline \multicolumn{5}{|l|}{ Gender } \\
\hline Male & 128 & 38.43 & 121 & 35.69 \\
\hline Female & 160 & 48.04 & 199 & 58.70 \\
\hline \multicolumn{5}{|l|}{ Ethnicity } \\
\hline Minority & 159 & 47.74 & 162 & 47.78 \\
\hline Majority & 174 & 52.25 & 177 & 52.21 \\
\hline \multicolumn{5}{|l|}{ Biology } \\
\hline Regular Biology & 258 & 77.47 & 213 & 62.83 \\
\hline AP Biology & 75 & 22.52 & 78 & 23.00 \\
\hline \multicolumn{5}{|l|}{ Chemistry } \\
\hline Regular Chemistry & 239 & 71.77 & 50 & 70.79 \\
\hline AP Chemistry & 48 & 14.44 & 240 & 14.74 \\
\hline \multicolumn{5}{|c|}{ School Financial Support } \\
\hline Yes & 180 & 54.05 & 193 & 56.93 \\
\hline No & 153 & 45.94 & 127 & 37.46 \\
\hline \multicolumn{5}{|l|}{ Work Hours } \\
\hline $0-5$ & 160 & 42.90 & 164 & 48.40 \\
\hline \multicolumn{5}{|l|}{ Major } \\
\hline Biology & 148 & 44.44 & 175 & 51.62 \\
\hline Other & 185 & 55.55 & 145 & 42.77 \\
\hline Successful & 188 & 56.45 & 157 & 46.31 \\
\hline Non Successful & 145 & 43.54 & 182 & 53.68 \\
\hline
\end{tabular}

\section{Results and Discussion}

Demographic Information Analysis: The trends in the data revealed similarity between students in cohort one and cohort two. To determine the similarity between cohorts, comparison of selected demographic variables- gender, ethnicity, high school GPA, high school chemistry, college major, school financial support, and work hours were conducted using a Chi-square test. The comparison of both cohorts' frequencies indicated that student participants were primarily freshmen and sophomores followed by juniors and seniors in both cohorts. With the exception of Organismal Biology in cohort two, female enrollment was almost ten percent higher than male 
enrollment. The gender difference between cohorts was not statistically significant in Functional Biology. However, the difference was statistically significant in Organismal Biology $\left(\mathrm{n}=565, \chi^{2}=8.684, p=0.003\right)$. The difference in ethnicity between cohorts was not statistically significant. High school GPA ranged from 2.00 to 4.00 in Functional and Organismal Biology in both cohorts. Less than $20 \%$ of student participants in both cohorts reported having taken AP high school chemistry. Similarly, less than $30 \%$ of students reported having taken high school AP biology in both cohorts. The difference, however, was not statistically significant between cohorts. In Functional and Organismal Biology, more than 50\% of students reported receiving some kind of school financial aid support in both cohorts. However, the difference was not statistically significant between cohorts. Regarding employment hours, almost $50 \%$ of students reported working less than five hours per week. $40 \%$ and $55 \%$ of students in both cohorts in Functional Biology and Organismal Biology respectively reported to be nonbiology majors. Four percent more cohort two students successfully completed Functional Biology than cohort one and almost ten percent more cohort two students successfully completed Organismal Biology than cohort one. In cohort one, $46.31 \%$ of the students in Organismal Biology and $56.45 \%$ in Functional Biology were successfully able to complete the course with a minimum grade of "C." The difference was statistically significant ( $\left.\mathrm{n}=624, \chi^{2}=5.158, p=0.023\right)$. In cohort two, $55.4 \%$ and $60.19 \%$ of students were successfully able to complete the course in Organismal Biology and Functional Biology respectively. The difference between cohorts, however, was not statistically significant. The frequencies and percent of selected demographic variables are presented in Table 1 and Table 2.

Table 2. Demographic Characteristics of Functional and Organismal Biology Student Participants of Cohort Two

\begin{tabular}{|c|c|c|c|c|}
\hline . & Functional Biology & & Organismal Biology & \\
\hline Variable & Frequency & Percent & Frequency & Percent \\
\hline \multicolumn{5}{|l|}{ Classification } \\
\hline Freshman & 119 & 37.89 & 63 & 22.10 \\
\hline Sophomore & 72 & 22.92 & 86 & 30.17 \\
\hline Junior & 57 & 18.15 & 68 & 23.85 \\
\hline Senior & 29 & 9.23 & 28 & 9.82 \\
\hline \multicolumn{5}{|l|}{ Gender } \\
\hline Male & 114 & 36.30 & 123 & 43.15 \\
\hline Female & 164 & 52.22 & 122 & 42.80 \\
\hline \multicolumn{5}{|l|}{ Ethnicity } \\
\hline Minority & 144 & 45.85 & 143 & 50.175 \\
\hline Majority & 170 & 54.14 & 142 & 49.82 \\
\hline \multicolumn{5}{|l|}{ Biology } \\
\hline Regular Biology & 214 & 68.15 & 176 & 61.75 \\
\hline AP Biology & 58 & 18.47 & 63 & 22.10 \\
\hline \multicolumn{5}{|l|}{ Chemistry } \\
\hline Regular Chemistry & 217 & 69.10 & 196 & 68.77 \\
\hline AP Chemistry & 34 & 10.82 & 37 & 12.98 \\
\hline \multicolumn{5}{|c|}{ School Financial Support } \\
\hline Yes & 178 & 56.68 & 165 & 57.89 \\
\hline No & 136 & 43.31 & 120 & 42.10 \\
\hline \multicolumn{5}{|l|}{ Work Hours } \\
\hline $0-5$ & 146 & 46.50 & 113 & 39.60 \\
\hline \multicolumn{5}{|l|}{ Major } \\
\hline Biology & 123 & 39.17 & 139 & 48.77 \\
\hline Other & 191 & 60.82 & 146 & 51.22 \\
\hline Successful & 189 & 60.19 & 158 & 55.43 \\
\hline Non Successful & 125 & 39.80 & 127 & 44.56 \\
\hline
\end{tabular}

Missing percent data not included

The results from the DIA indicated that freshmen were higher in numbers in both entry-level biology courses followed by sophomores, juniors, and seniors. However, it would be expected that freshmen enrollment would dominate these courses because these courses are the initial prerequisite courses for those who are interested in pursuing biology major. The analysis indicated that only half of the student participants enrolled in entry-level biology courses were biology majors and out of those, again, only 58\% were able to successfully complete the course. Some studies suggest that an inappropriate choice of college majors lowers students' interest towards the subject area. The effects of the declining interest eventually feed into the departure problem (DelVecchio \& Honeycutt, 2002; DeMarie \& Aloise-Young, 2003; Feldman, Smart, \& Ethington, 1999; Francisco, Noland, \& Kelly, 2003; Galotti, 1999; Kimweli\& Richards, 1999; LaBarbera \& Simonoff, 1999; Lackland \& DeLisi, 2001; Malgwi, Howe, \& Burnaby, 2005; Seymour \& Hewitt,
1997; NSB, 2010; St. John, 2000; Turner \& Bowen, 1999). Given this low success rate, there are some important questions we as biology or science educators must ask ourselves and our institutions or departments: If approximately half of our biology students are not biology majors, whom do we want to retain? How can this problem be resolved? Increasing students' knowledge, positive attitude, and confidence may be a viable method to increase student interest in biology. This will not quickly eliminate the current problem of low student performance and success in entry-level biology majors' courses. However, it will be more likely to improve instructional climate and reciprocally improve the biology education of both non STEM majors and majors alike. A study conducted by Sundberg, Dini, and Li (1994) indicated that the level of biology knowledge and confidence or positive attitude toward biology were related to higher student achievement in introductory biology courses. The study compared the mean pre-test of 
biology majors and non-majors. The results suggest that students who were enrolled in a biology major course had more biology knowledge and a more positive attitude than their non-biology major peers. Furthermore, Tai, Sadler, and Loehr (2005) suggest that high school courses in biology, chemistry, and physics prepare students for college courses in the same field. Additionally, at the institutional level, Astin (1984) revealed that student choice of major affects student success rate. At the departmental level, success in entry-level courses affects students' choice of future majors. The learning experiences students gain during high school has the foremost effect in developing their later interest. The most revealing finding from the present study was that regardless of their major, high school biology experiences were less likely to have an effect on college biology performance and success.

\section{Logistic Regression Analysis}

The results are reported for the overall sample, Cohorts one and two separately. Cohort one consists of students enrolled in entry-level biology courses in the fall 2007. For LRA, student success was the dependent variable, which was based on final course grades categorized as successful (students receiving a minimum of a grade "C" or higher) and not successful (students receiving a grade of "D," "F," or "W"). Therefore, the dependent variable was dichotomous with a " 1 ” indicating successful and a " 0 " indicating non-successful. Therefore, a series of logistic regression analyses were conducted to answer research questions six through eight. Seven variablesgender, ethnicity, high school GPA, high school science, school major, school financial support, and work hours were used as possible predictor variables of student success. All possible predictor variables except high school GPA (which is a continuous variable) were dummy-coded as zeros and ones. LRA of the sample of all students in entry-level biology courses (Table 3) showed that out of seven predictor variables only four variablesschool financial support, ethnicity, high school GPA and high school chemistry had the recommended Wald statistic of $p<0.25$. Therefore, only these four variables were used for further modeling. The variable high school chemistry had a statistically significant Wald statistic ( $p=$ 0.011 ) indicating that the odds of a student who had taken high school chemistry was (odds ratio $=1.435, p<0.011$ ) more likely to be successful in entry-level biology courses than the odds of those who had not. Similarly, the odds of a student who had a high school GPA of 2.7 or higher (odds ratio $=1.771, p<0.00$ ) was more likely to be successful than the odds of those who had not. Additionally, the Confidence Interval (CI) of the odds ratio did not contain " 1 " indicating that student having taken high school chemistry is a good predictor of being successful in entry-level biology courses.

Table 3. Summary of LRA Predicting if Students were Successful (combined sample)

\begin{tabular}{|c|c|c|c|c|c|c|c|}
\hline Variable & $\beta$ & SE & Wald & $p$-value & Odds ratio $\operatorname{Exp}(\mathrm{B})$ & \multicolumn{2}{|c|}{$\begin{array}{l}\text { 95\% CI for odds ratio } \\
\text { Lower Upper }\end{array}$} \\
\hline School Financial Support & 0.169 & 0.142 & 1.428 & 0.232 & 1.185 & 0.897 & 1.564 \\
\hline High School Chemistry & 0.361 & 0.142 & 6.453 & 0.011 & 1.435 & 1.086 & 1.897 \\
\hline Ethnicity & 0.151 & 0.136 & 1.230 & 0.267 & 1.163 & 0.91 & 1.517 \\
\hline High school GPA & 0.572 & 0.153 & 14.03 & 0.000 & 1.771 & 0.988 & 1.003 \\
\hline Constant & -2.143 & 0.561 & 14.59 & 0.000 & 0.117 & & \\
\hline
\end{tabular}

Sample 1. The LRA of the sample of all students in entry-level biology courses showed that out of seven predictor variables only three variables-gender, ethnicity, and high school chemistry had the recommended Wald statistic of $p<0.25$ (Table 4). Therefore, only these three variables were used for further modeling. The variable high school chemistry had a statistically significant Wald statistic $(p=0.042)$ indicating that students having taken high school chemistry were (odds ratio $=1.702, p<0.027$ )

more likely to be successful in entry-level biology courses than those who had not. Additionally, the Confidence Interval (CI) of the odds ratio does not contain " 1 " indicating that student having taken high school chemistry is a good predictor of being successful in entry-level biology courses. It was also found that the Wald statistic value of gender was approaching statistical significant level indicating that female students were more likely to be successful in this course.

Table 4. Summary of Logistic Regression Analysis Predicting if Students were Successful in Entry-Level Biology in Cohort One

\begin{tabular}{|c|c|c|c|c|c|c|c|}
\hline Variable & $\beta$ & SE & Wald & $p$-value & Odds ratio Exp(B) & \multicolumn{2}{|c|}{$\begin{array}{c}\text { 95\% CI for odds ratio } \\
\text { Lower Upper }\end{array}$} \\
\hline Gender & 0.32 & 0.17 & 3.49 & 0.06 & 1.38 & 0.984 & 1.954 \\
\hline Ethnicity & -0.27 & 0.17 & 2.41 & 0.12 & 0.76 & 0.537 & 1.074 \\
\hline High School Chemistry & 0.53 & 0.24 & 4.85 & 0.02 & 1.70 & 1.060 & 2.733 \\
\hline
\end{tabular}

Sample 2. The logistic regression analysis of the sample of all students in entry-level biology courses showed that out of seven predictor variables only two variables-high school GPA and school financial support had the recommended Wald statistic of $p<0.25$. Therefore, only these two variables were used for further modeling. It was found that the Wald statistic of both school financial support and high school GPA were statistically significant indicating students with higher high school GPA were (odds ratio $=2.014, p=0.001$ ) more likely to be successful in entry-level biology courses. The CI of the odds ratio did not contain " 1 " indicating that high school GPA was a good predictor of being successful in entry-level biology course. School financial support also approached significance level indicating students who were supported by school financial support were (odds ratio=1.42, $p$ $=0.075$ ) more likely to be successful in the course compared to those who did not receive. The results are presented in Table 5. 
Table 5. Summary of LRA Predicting if Students were Successful in Entry-Level Biology in Cohort Two

\begin{tabular}{|c|c|c|c|c|c|c|}
\hline Variable & $\beta$ & SE & Wald & p-value & \multicolumn{2}{|c|}{$\begin{array}{c}\text { Odds ratio Exp(B) CI for odds ratio } \\
\text { Lower Upper }\end{array}$} \\
\hline High School GPA & 0.7 & 0.217 & 10.399 & 0.001 & 2.014 & 1.316 \\
\hline School Financial Support & 0.35 & 0.197 & 3.174 & 0.075 & 1.42 & 0.966 \\
\hline
\end{tabular}

The LRA results suggest that for all samples, students' high school GPA was a significant predictor of student success. Other predictors for samples 1 and 2 included gender, ethnicity, and having taken high school chemistry. For samples of students in cohort two, high school GPA was a consistent predictor of student success. Other predictors for various samples included school financial support, ethnicity, and having taken high school chemistry. The results from Functional and Organismal Biology in cohort one, independently, showed that high school chemistry was a more likely predictor of student success in entry-level biology courses. Similarly, the results from all student analysis in cohort one indicated that students who had taken high school chemistry were more likely to be successful in entry-level biology courses. The analysis of all students revealed that high school GPA and high school chemistry were strongly associated with students' performance in entry-level biology courses. High school GPA as a predictor of student success in an introductory biology course is supported by several studies (Gibson \& Gibson, 1993; Mitchell \& Lawson, 1988; Tamir, 1969; Tamir, Amir, \& Nussinovitz, 1980; Korey, 2013; Belfield \& Crosta, 2014; Farkas, 2014; Strauss, 2014). The present study suggests high school GPA as one of the best predictors of students' performance and success in entrylevel science courses.

\section{Recommendations}

These findings should not be interpreted as how well students perform in each class taught by different instructors, but as predictors of performance in entry-level science courses based on what students learn in these courses and their demographic and academic characteristics. Based on the present results, if a model is developed incorporating students' high school academic background, the model will predict student success at the course specific level. The previous studies on students' high school science academic background indicated mix results. These differences in results were likely due to the fact that each study is unique in nature and is being conducted at different scales using different units of analysis. To assess students' success at course specific levels, this equation can be effectively utilized.

\section{Acknowledgements}

I would like my committee members for providing this opportunity to conduct this study.

\section{References}

[1] American Council on Education. (1996). Remedial education: An undergraduate student profile. Washington, DC: Author.

[2] Astin, A. W. (1984). Student involvement: A development theory for higher education. Journal of College Student Personal, 25, 297-308.
[3] Bendel, R. B., \& Afifi, A. A. (1977).Comparison of stopping rules in forward regression. Journal of the American Statistical Association, 72, 46-53.

[4] Belfield. C. \&Crosta, P.M. (2014). Predicting Success in College: The Importance of Placement Tests and High School Transcripts. Retrieved on March 14th 2014 from http://ccrc.tc.columbia.edu/publications/predicting-successplacement-tests-transcripts.html.

[5] Cambiano, R. L., Denny, G. S., \& De Vore, J. B. (2000). College student retention at a midwestern university: A six-year study. Journal of Higher Education, 166, 143-164.

[6] DesJardins, S. L., McCall, B. P., Ahlburg, D. A., \&Moye, M. J. (2002). Adding a timing light to the "tool box." Research in Higher Education, 43, 83-114.

[7] Farkas, K. (2014). School grades as good a predictor of college success as SAT or ACT, report says: Higher Education Roundup. Retrieved on March 14th 2014 from http://www.cleveland.com/metro/index.ssf/2014/02/high_school_g rades_better_pred.html.

[8] Gibson, D. J., \& Gibson, L. S. (1993). College students' perception on adequacy of high school science curriculum as preparation for college level biology. The American Biology Teacher, 55, 8-12.

[9] Hosmer, D. W., \& Lemeshow, S. (Eds.). (2000).Applied Logistic Regression. New York: Wiley.

[10] House, J. D. (1995). Noncognitive predictors of achievement in introductory college chemistry. Research in Higher Education, 36, 473-490.

[11] Hu, S., and St. John, E. P. (2001). Student persistence in a public higher education system:

[12] Understanding racial and ethnic differences. Journal of Higher Education 72 (3): 265-86.

[13] Jones, D. J., \& Watson, B. C. (1990). "High risk" students and higher education: Future trends. (ASHE-ERIC Higher Education Report No. 3). Washington, DC: The George Washington University, School of Education and Human Development.

[14] Jones, D. J., \& Watson, B. C. (1990). High-risk students and higher education: Future trends. ASHE-ERIC higher education report no. 3.

[15] Kahveci, A., Southerland, S. A., \& Gilmer, P. J. (2006).Retaining undergraduate women in Science, Mathematics, and Engineering. Journal of College Science Teaching, 36, 34-38.

[16] Korey, E. (2013). A new formula for college success. Retrieved on March 14th 2014 from http://www.uakron.edu/im/onlinenewsroom/news_details.dot?newsId=41321aee-0ffa-454da4999aacab6d3139\&crumbTitle=A\%20new\%20formula\%20for\% 20college\%20success\#.UyNzjfldWRQ.

[17] Kulik, C-L., Kulik, J., \&Schwalb, B. (1983). College programs for high risk and disadvantaged students: A meta-analysis of findings. Review of Educational Research, 53, 397-414.

[18] Leppel, K. (2002). Similarities and differences in the college persistence of men and women. Review of Higher Education 25, 433-450.

[19] Mitchell, A., \& Lawson, A. E. (1988).Predicting genetics achievement in non-majors college biology. Journal of Research in Science Teaching, 25, 23-37.

[20] National Research Council (NRC). (1996). National science education standards. No. National Academy Press. Washington: D.C.

[21] National Science Board (NSB). (2010). preparing the next generation of STEM innovators: Identifying and developing our nation's human capital. Arlington, VA:

[22] Pascarella, E. T., \& Terenzini, P. T. (1980).Predicting freshman persistence and voluntary dropout decisions from a theoretical model. The Journal of Higher Education, 51, 60-75.

[23] Perna, L. W. (1997). The contribution of financial aid to undergraduate persistence. Paper presented at the 22 th annual forum of the Association for Study of Higher Education, Albuquerque, NM Sadler, P. M., \& Tai, R. H. (2000). Success in introductory college physics: The role of high school preparation. Science Education, 85, 111-136. 
[24] Solak, R. R., \&Rohlf, F. J. (Eds.) (1995). Biometry: The Principles and Practice of Statistics in Biological Research. W. H. Freeman and Co.: New York.

[25] Selingo J. (2003). What Americans think about higher education? The Chronicle of Higher Education. pp. A 10-A 17.

[26] Singh, M. (2009).Student Performance and Success in Entry-Level Undergraduate Biology Courses. Four Year University and College Section Research Symposium National Association of Biology Teachers 2009 Professional Development Conference November 12, 2009, Denver, Colorado.

[27] Strauss, V. (2014). High school grades best predictor of college success-not SAT/ACT scores. Retrieved on March 14th 2014 from http://www.washingtonpost.com/blogs/answersheet/wp/2014/02/21/a-telling-study-about-act-sat-scores/
[28] Tai, R. H., Sadler, M. S., and Loehr, J. F. (2005 (2005).Factors Influencing Success in Introductory College Chemistry. Journal of Research in Science Teaching, 42, 987-1012

[29] Tamir, P. (1969). High school preparation and college biology. BioScience, 19, 447-449.

[30] Tamir, P., Amir, R., \& Nussinovitz, R. (1980).High school preparation for college biology in Israel. Higher Education, 9, 399-408.

[31] Tinto, V. (1982).Links of theory and practice in student attrition. Journal of Higher Education, 53, 687-700.

[32] Weissberg, N. C., Owen, D. R., Jenkins, A. H., \&Harburg, E. (2003). The incremental variance problem: Enhancing the predictability of academic success in an urban, commuter institution. Genetic, Social, and General Psychology Monographs, $129,153-180$. 